\title{
Kisspeptin stimulation of insulin secretion: mechanisms of action in mouse islets and rats
}

\author{
J. E. Bowe • A. J. King • J. S. Kinsey-Jones • V. L. Foot • \\ X. F. Li • K. T. O'Byrne • S. J. Persaud • P. M. Jones
}

Received: 29 October 2008 / Accepted: 16 January 2009 / Published online: 17 February 2009

(C) Springer-Verlag 2009

\begin{abstract}
Aims/hypothesis Kisspeptin is a novel peptide identified as an endogenous ligand of the G-protein-coupled receptor 54 (GPR-54), which plays a crucial role in puberty and reproductive function. High levels of GPR-54 and kisspeptin have been reported in the pancreas and we have previously shown that kisspeptin potentiates glucose-induced insulin release from isolated islets, although the mechanisms underlying this effect were unclear.

Methods Insulin secretion from isolated mouse islets was measured to characterise the effects of kisspeptin. The effects of kisspeptin on both p42/44 mitogen-activated protein kinase (MAPK) phosphorylation and intracellular $\mathrm{Ca}^{2+}\left(\left[\mathrm{Ca}^{2+}\right]_{\mathrm{i}}\right)$ in mouse islets were also investigated. Furthermore, kisspeptin was administered to rats in vivo and effects on plasma insulin levels measured.

Results In the current study, kisspeptin induced a concentration-dependent potentiation of glucose-induced $(20 \mathrm{mmol} / \mathrm{l})$ insulin secretion from mouse islets, with maximal effects at $1 \mu \mathrm{mol} / \mathrm{l}$, but had no effect on insulin secretion at a substimulatory concentration of glucose $(2 \mathrm{mmol} / \mathrm{l})$. Activation of GPR-54 by kisspeptin also caused reversible increases in $\left[\mathrm{Ca}^{2+}\right]_{\mathrm{i}}$ in Fura-2 loaded dispersed islet cells.
\end{abstract}

J. E. Bowe $(\bowtie) \cdot$ A. J. King $\cdot$ V. L. Foot $\cdot$ S. J. Persaud $\cdot$

P. M. Jones

Beta Cell Development and Function Group,

Division of Reproduction and Endocrinology,

School of Biomedical and Health Sciences,

King's College London,

London SE1 1UL, UK

e-mail: james.bowe@kcl.ac.uk

J. S. Kinsey-Jones $\cdot$ X. F. Li $\cdot$ K. T. O’Byrne

Division of Reproduction and Endocrinology,

School of Biomedical and Health Sciences,

King's College London,

London, UK
The kisspeptin-induced potentiation of glucose-induced insulin secretion was completely abolished by inhibitors of phospholipase C and p42/44 MAPK, but not by inhibitors of protein kinase $\mathrm{C}$ or p38 MAPK. Intravenous administration of kisspeptin into conscious, unrestrained rats caused an increase in circulating insulin levels, whilst central administration of kisspeptin had no effect, indicating a peripheral site of action.

Conclusions/interpretation These observations suggest that neither typical protein kinase $\mathrm{C}$ isoforms nor p38 MAPK are involved in the potentiation of glucose-induced insulin release by kisspeptin, but intracellular signalling pathways involving phospholipase C, p42/44 MAPK and increased $\left[\mathrm{Ca}^{2+}\right]_{\mathrm{i}}$ are required for the stimulatory effects on insulin secretion. The observation that kisspeptin is also capable of stimulating insulin release in vivo supports the conclusion that kisspeptin is a regulator of beta cell function.

Keywords Beta cell · GPR-54 · Insulin · Islet · Kisspeptin
Abbreviations
$\left[\mathrm{Ca}^{2+}\right]_{\mathrm{i}}$ Intracellular $\mathrm{Ca}^{2+}$ concentration
DAG Diacylglycerol
GPR-54 G-protein-coupled receptor 54
i.c.v. Intracerebroventricular
MAPK Mitogen-activated protein kinase
PKC Protein kinase C
PLC Phospholipase C
PMA Phorbol 12-myristate 13-acetate

\section{Introduction}

Kisspeptins are a family of peptides encoded by the KISS1 gene which have been identified as the endogenous ligands 
for the G-protein-coupled receptor 54 (GPR-54). KISS1 was originally identified in breast cancer and melanoma cell lines as a metastasis suppressor gene involved in the inhibition of tumour progression [1-3]. It has since been shown to play a pivotal role in the control of the hypothalamo-pituitarygonadal axis, where it regulates the onset of puberty $[4,5]$. Studies using fasted or obese animals have also suggested that hypothalamic kisspeptin may play an important role in mediating the inhibitory effects of nutritional status on reproductive function, implying a possible role as a wholebody energy sensor [6, 7]. However, the functions of kisspeptin and GPR-54 are not confined to hypothalamic neurones, since both are expressed in various peripheral tissues including, at particularly high levels, in the pancreas [3]. We have recently identified the site of pancreatic kisspeptin and GPR-54 content as being exclusively in the endocrine pancreas, consistent with a peripheral role in whole-body fuel homeostasis [8]. We have also demonstrated that in addition to its hypothalamic effects, kisspeptin stimulates the release of insulin from isolated mouse and human islets [8]. The established role of kisspeptin in mediating the effects of altered nutritional status on reproductive function, combined with the ability of kisspeptin to stimulate insulin release and the importance of pancreatic beta cells as regulators of fuel homeostasis, suggests a potential physiological role for kisspeptin in regulating islet function. The present study was undertaken to further characterise the stimulatory effect of kisspeptin on insulin release, and to determine whether the kisspeptin and GPR-54 system represents a novel regulator of beta cell function.

\section{Methods}

Materials Mouse kisspeptin-10 was supplied by Phoenix Pharmaceuticals (Karlsruhe, Germany). The protein kinase C (PKC) inhibitor Gö6976, the phospholipase C (PLC) inhibitor U73122, the p42/44 mitogen-activated protein kinase (MAPK) inhibitor PD98059 and the p38 MAPK inhibitor SB203580 were from Calbiochem (Nottingham, UK). All inhibitors were dissolved in DMSO such that the final DMSO concentration in incubation buffers was $0.1 \%$ (vol./vol.). The relevant controls received 0.1\% DMSO (vol./ vol.) alone. Fura-2/AM, collagenase, fetal calf serum, penicillin, glutamine and streptomycin were from Sigma (Poole, UK). RPMI was supplied by Invitrogen (Paisley, UK). The antibodies against total p42/44 MAPK $(1: 2,000)$ and against phosphorylated p42/44 MAPK $(1: 2,500)$ were obtained from Promega (Southampton, UK). Ketamine was supplied by Pharmacia \& Upjohn (Crawley, UK) and rompun by Bayer (Leverkusen, Germany). Fluid swivels and spring tethers for i.v. cannulation were from Instec Laboratories (Boulder, CO, USA). Blood glucose meters were from Boehringer Mannheim (Mannheim, Germany).

Islet isolation and maintenance Islets of Langerhans were isolated from male ICR mice (Harlan, Bicester, UK) by collagenase digestion of the exocrine pancreas and incubated at $37^{\circ} \mathrm{C}$ in RPMI (supplemented with $10 \%$ [vol./vol.] fetal calf serum, $2 \mathrm{mmol} / 1$ glutamine and $100 \mathrm{U} / \mathrm{ml}$ penicillin/ $0.1 \mathrm{mg} / \mathrm{ml}$ streptomycin) for at least $24 \mathrm{~h}$ before use.

Insulin secretion in vitro The effects of kisspeptin on insulin secretion from mouse islets were assessed using either a temperature-controlled perifusion apparatus, essentially as described previously [9], or in static incubations of islets. For perifusion experiments, groups of 40 islets were perifused with a bicarbonate-buffered physiological salt solution $\left(0.5 \mathrm{ml} / \mathrm{min}, 37^{\circ} \mathrm{C}\right.$, [10]) containing $2 \mathrm{mmol} / 1$ glucose, $2 \mathrm{mmol} / 1 \mathrm{CaCl}_{2}$ and $0.5 \mathrm{mg} / \mathrm{ml} \mathrm{BSA}$. Samples of perifusate were taken at $2 \mathrm{~min}$ intervals and stored at $-20^{\circ} \mathrm{C}$ until assayed for insulin content.

For static incubations islets were pre-incubated for $2 \mathrm{~h}$ in RPMI containing $2 \mathrm{mmol} / \mathrm{l}$ glucose. Groups of three islets were transferred into $1.5 \mathrm{ml}$ Eppendorf tubes and incubated at $37^{\circ} \mathrm{C}$ for $1 \mathrm{~h}$ in physiological salt solution as described above, supplemented with agents of interest. After $1 \mathrm{~h}$, samples of the incubation medium were taken and stored at $-20^{\circ} \mathrm{C}$ until assayed for insulin content.

The insulin content of perifusion and static incubation samples was determined using an in-house radioimmunoassay [11].

Calcium microfluorimetry Islets were dissociated in $0.02 \%$ (wt/vol.) EDTA, cells were seeded onto acid-ethanol-washed glass cover slips (100,000 cells/cover slip) and allowed to adhere overnight in RPMI under standard tissue culture conditions. Changes in intracellular calcium were measured by calcium microfluorimetry using Fura-2/AM, as described previously [12]. Cells were perifused with a salt solution supplemented with $2 \mathrm{mmol} / \mathrm{l}$ glucose and substances of interest. Fluorescence data were collected every $3 \mathrm{~s}$ and expressed as a $340: 380$ ratio.

Measurement of MAPK activation Groups of 200 islets were incubated $\left(37^{\circ} \mathrm{C}, 5 \mathrm{~min}\right)$ in a physiological salt solution containing either $2 \mathrm{mmol} / 1$ or $20 \mathrm{mmol} / 1$ glucose in the presence or absence of $1 \mu \mathrm{mol} / \mathrm{l}$ kisspeptin, then cooled and pelleted by centrifugation $(10,000 \mathrm{~g}, 1 \mathrm{~min})$. The supernatant fraction was discarded and protein extracts were prepared as described [13]. Proteins were separated by PAGE, transferred to membranes and immunoprobed for p42/44 MAPK and for phosphorylated (activated) MAPK, as described previously [13]. 
Insulin secretion in vivo Adult Wistar rats (B\&K, Battlesbridge, UK), were housed under controlled conditions (14:10 h light:dark; lights on at 07:00; temperature $22 \pm 2^{\circ} \mathrm{C}$ ) and provided with food and water ad libitum. All animal procedures were undertaken in accordance with the UK Home Office Regulations. All surgical procedures were carried out with ketamine (100 mg/kg i.p.) and rompun (10 mg/kg i.p.) anaesthesia. Rats were chronically implanted with an intracerebroventricular (i.c.v.) guide cannula, positioned into the left lateral cerebral ventricle as described previously [14]. Following a 10 day recovery period rats were fitted with two indwelling cardiac catheters via the jugular veins [14]. The catheters were exteriorised at the back of the head and secured to a cranial attachment: the rats were fitted with a $30 \mathrm{~cm}$ long metal spring tether. The distal end of the tether was attached to a fluid swivel, which allowed the rat freedom to move around the enclosure. Experimentation commenced 3 days later.

Experiments commenced between 09.30 and 10.30 hours. Blood samples $(0.25 \mathrm{ml})$ were drawn manually from one of the catheters to determine blood glucose concentrations, measured using a Reflolux S blood glucose monitor, and to obtain plasma samples that were stored for later insulin radioimmunoassay. Blood samples taken immediately before and after kisspeptin administration were assayed to determine the increase in circulating levels of kisspeptin using a commercially available human kisspeptin ELISA (Phoenix Pharmaceuticals). After $30 \mathrm{~min}$, animals were injected with either $37.5 \mathrm{nmol}$ kisspeptin i.v. or $3.75 \mathrm{nmol}$ kisspeptin i.c.v., based on kisspeptin concentrations used in previous studies to stimulate plasma luteinising hormone release $[15,16]$. Blood samples were taken at the following time points, $-30,-5,+15,+30,+60,+120$ and $+240 \mathrm{~min}$ relative to the injection of kisspeptin.

Statistical analysis Secretion data are expressed as means \pm SEM. Statistical analyses were performed using ANOVA or Student's $t$ tests as appropriate and $p<0.05$ was considered significant.

\section{Results}

Effect of kisspeptin on insulin secretion from mouse islets in vitro Kisspeptin potentiated glucose-induced insulin secretion from isolated, perifused mouse islets in a reversible manner, as shown in Fig. 1a. Increasing the glucose concentration in the perifusate from a basal of $2 \mathrm{mmol} / \mathrm{l}$ glucose to a maximal stimulatory concentration of $20 \mathrm{mmol} / \mathrm{l}$ glucose initiated a biphasic insulin secretory response and the addition of $1 \mu \mathrm{mol} / \mathrm{l}$ kisspeptin during the stable second phase of glucose-induced secretion induced an approximately three-
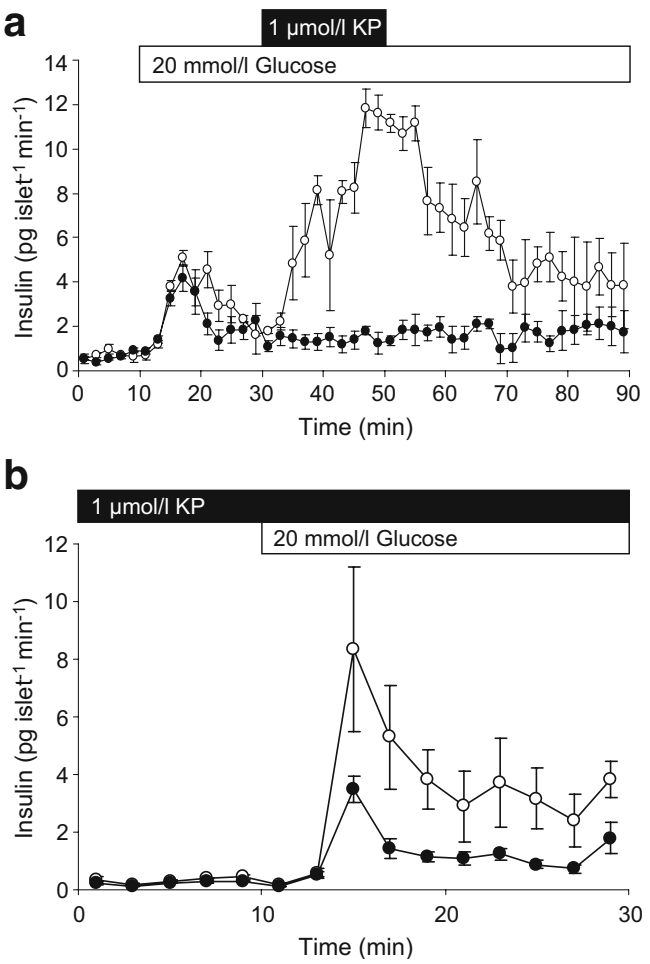

Fig. 1 Kisspeptin enhances glucose-induced insulin secretion from mouse islets. a Increasing the glucose concentration from $2 \mathrm{mmol} / \mathrm{l}$ (0-10 $\mathrm{min})$ to $20 \mathrm{mmol} / \mathrm{l}$ (white bar) induced a biphasic stimulation of insulin secretion from mouse islets. Exposure to kisspeptin (1 $\mu \mathrm{mol} / 1,30-50 \mathrm{~min}$, white circles) enhanced the second, plateau phase of insulin secretion over that induced by $20 \mathrm{mmol} / \mathrm{l}$ glucose alone (black circles). Following withdrawal of kisspeptin, insulin secretion returned to the previous glucose-stimulated plateau levels. Mean \pm SEM, $n=8$. b Exposure to kisspeptin $(1 \mu \mathrm{mol} / 1,0-30 \mathrm{~min}$, white circle) had no effect on insulin secretion at basal glucose levels ( $2 \mathrm{mmol} / 1,0-10 \mathrm{~min})$, but enhanced both the first and second phases of glucose-induced insulin release compared with release from islets treated with glucose alone (black circle). Mean \pm SEM, $n=8$. KP, kisspeptin

fold increase in insulin release ( $p<0.01$ vs second-phase glucose-induced secretion). Following the removal of kisspeptin, insulin secretion returned to the second-phase, glucose-induced levels. Figure $1 \mathrm{~b}$ shows similar experiments in which the perifused islets were exposed to kisspeptin $(1 \mu \mathrm{mol} / \mathrm{l})$ at the same time as $20 \mathrm{mmol} / \mathrm{l}$ glucose. The presence of kisspeptin significantly $(p<0.01)$ enhanced the first rapid phase of glucose-induced insulin secretion in addition to inducing a maintained elevation in the second, plateau phase of the secretory response.

The effects of kisspeptin on glucose-induced insulin secretion from perifused mouse islets (Fig. 1) were consistent with the results of experiments using static incubations of mouse islets, as shown in Fig. 2. Thus, kisspeptin $(100 \mathrm{pmol} / \mathrm{l}-1 \mu \mathrm{mol} / \mathrm{l})$ had no effect on insulin secretion in the presence of a substimulatory concentration of glucose ( $2 \mathrm{mmol} / \mathrm{l}$ ), but potentiated $20 \mathrm{mmol} / \mathrm{l}$ glucose-induced 
a

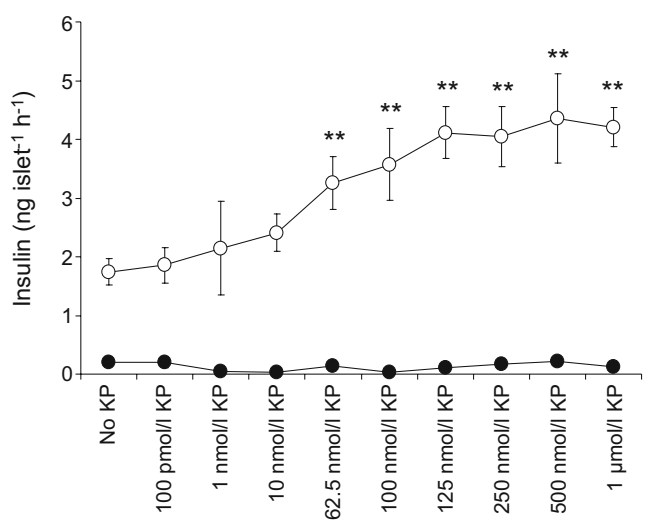

b

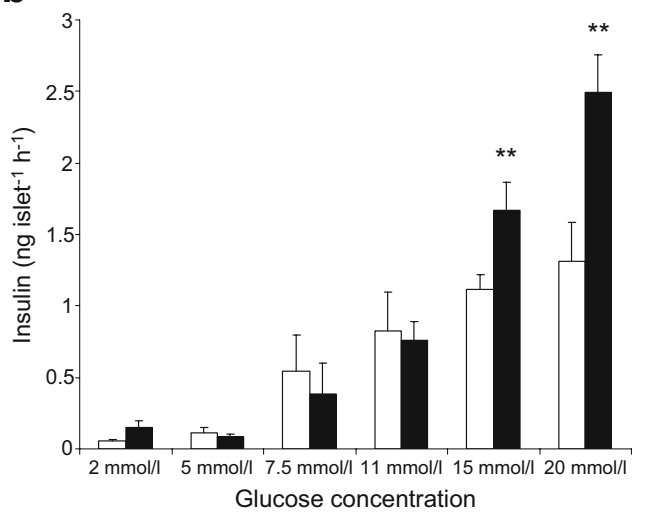

C

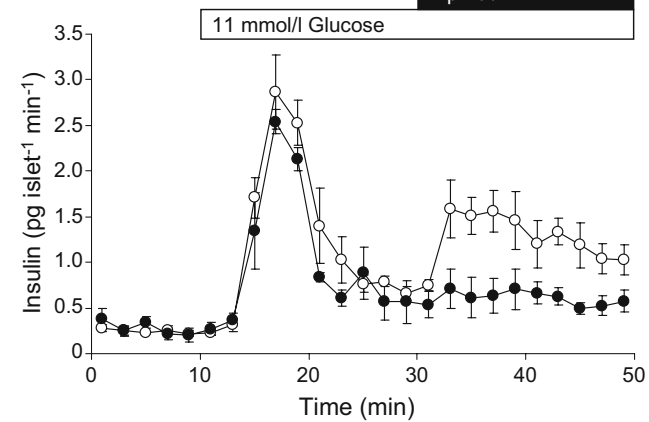

Fig. 2 In vitro concentration and glucose dependency of the effects of kisspeptin on insulin secretion. a In the presence of $20 \mathrm{mmol} / \mathrm{l}$ glucose (white circles), insulin release was potentiated in a kisspeptinconcentration-dependent manner. Kisspeptin concentrations of $62.5 \mathrm{nmol} / 1$ or higher were required for a significant effect on insulin secretion. At $2 \mathrm{mmol} / \mathrm{l}$ glucose (black circles), kisspeptin had no effect at any concentration tested. Mean \pm SEM, $n=9, * * p<0.01$ vs $20 \mathrm{mmol} / \mathrm{l}$ glucose alone. b In static incubation experiments, kisspeptin significantly potentiated insulin release at glucose levels of $15 \mathrm{mmol} / \mathrm{l}$ and higher in vitro. Results from systems with 100 $\mathrm{nmol} / 1$ kisspeptin are shown in black, and those from systems without kisspeptin are shown in white. Mean \pm SEM, $n=9,{ }^{* *} p<0.01$ vs absence of kisspeptin. c In perifusion experiments, exposure to kisspeptin $(1 \mu \mathrm{mol} / 1,30-50 \mathrm{~min})$ enhanced the second, plateau phase of insulin secretion compared with that induced by $11 \mathrm{mmol} / 1$ glucose alone. Results for islets exposed to kisspeptin are shown as white circles; results for control islets, exposed to glucose only, are shown as black circles. Mean \pm SEM, $n=8$. KP, kisspeptin insulin secretion in a concentration-dependent manner, significantly stimulating insulin release at concentrations of $62.5 \mathrm{nmol} / \mathrm{l}$ and above (Fig. 2a). The stimulatory effects of kisspeptin were dependent on the presence of a stimulatory concentration of glucose, as shown in Fig. $2 b$ and c. In static incubation experiments (Fig. 2b) kisspeptin (100 nmol/l) had no significant effects on insulin secretion at glucose concentrations lower than $15 \mathrm{mmol} / \mathrm{l}$ (Fig. 2b) but perifusion experiments, which allow a more sensitive assessment of changes in the rate of insulin secretion, revealed that kisspeptin $(1 \mu \mathrm{mol} / \mathrm{l})$ enhanced insulin secretion at a glucose concentration of $11 \mathrm{mmol} / \mathrm{l}$ which is within the physiological postprandial range for a mouse (Fig. 2c).

Intracellular mechanisms involved in kisspeptin-induced insulin secretion The intracellular signalling pathways involved in the kisspeptin-induced potentiation of insulin release were investigated using pharmacological inhibitors of effector systems known to be important in beta cells. Figure $3 \mathrm{a}$ shows that the kisspeptin-induced potentiation of glucose-stimulated insulin release was inhibited by both the PLC inhibitor, U73122 $(10 \mu \mathrm{mol} / \mathrm{l})$, and the p42/44 MAPK inhibitor, PD98059 $(50 \mu \mathrm{mol} / \mathrm{l})$. In contrast, inhibitors of p38 MAPK, SB203580 $(50 \mu \mathrm{mol} / \mathrm{l})$, and of diacylglycerol (DAG)-dependent PKC isoforms, Gö6976 (1 $\mu \mathrm{mol} / \mathrm{l})$, had no effect on kisspeptin-induced insulin secretion. The possible role of DAG-dependent PKC isoforms in mediating the effects of kisspeptin was further investigated using islets in which PKC activity was downregulated by $24 \mathrm{~h}$ treatment with $500 \mathrm{nmol} / 14 \beta$-Phorbol 12-myristate 13 -acetate (PMA) $[17,18]$, shown in Fig. 3b. PKC downregulation was demonstrated by the loss of subsequent PMA-induced insulin secretory responses in islets pre-treated with $4 \beta$ PMA, compared with control islets treated with the inactive phorbol ester, $4 \alpha$-PMA. In contrast, the $4 \beta$-PMA-treated islets showed identical secretory responses to control islets treated with the inactive $4 \alpha$-PMA when challenged with $20 \mathrm{mmol} / \mathrm{l}$ glucose alone or with $1 \mu \mathrm{mol} / \mathrm{l}$ kisspeptin in the presence of $20 \mathrm{mmol} / 1$ glucose $(108 \pm 5 \%$ and $112 \pm 11 \%$ vs $4 \alpha$-PMA treated islet responses, respectively, $n=9, p>0.2$ ).

Figure $3 \mathrm{c}, \mathrm{d}$ shows that $20 \mathrm{mmol} / \mathrm{l}$ glucose induced a rapid (5 min) increase in phosphorylated p42/44 MAPK in islets when compared with those maintained in $2 \mathrm{mmol} / \mathrm{l}$ glucose. However, kisspeptin $(1 \mu \mathrm{mol} / \mathrm{l})$ had no detectable effect on p42/44 MAPK activation at either glucose concentration. In dispersed mouse islet cells, $1 \mu \mathrm{mol} / 1$ kisspeptin caused an increase in intracellular calcium concentration $\left(\left[\mathrm{Ca}^{2+}\right]_{\mathrm{i}}\right)$ when administered either at $2 \mathrm{mmol} / \mathrm{l}$ or $20 \mathrm{mmol} / 1$ glucose, although a greater proportion of cells responded at $20 \mathrm{mmol} /$ 1 glucose (Fig. $4 ; 12 / 67$ cells [18\%] at $2 \mathrm{mmol} / 1$ glucose; $40 / 67$ cells $[60 \%]$ at $20 \mathrm{mmol} / 1$ glucose; data from seven separate experiments). Only cells that exhibited an increase in $\left[\mathrm{Ca}^{2+}\right]_{\mathrm{i}}$ in response to both $20 \mathrm{mmol} / \mathrm{l}$ glucose 
a

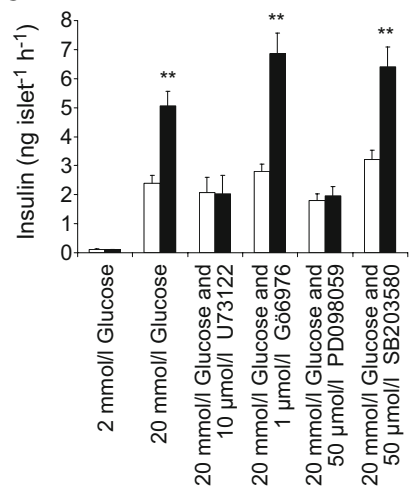

C

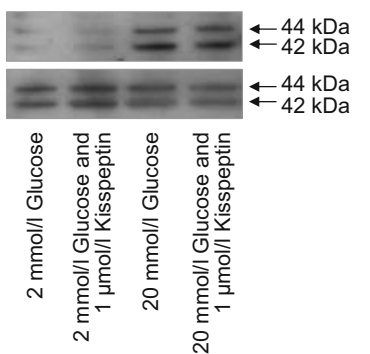

b

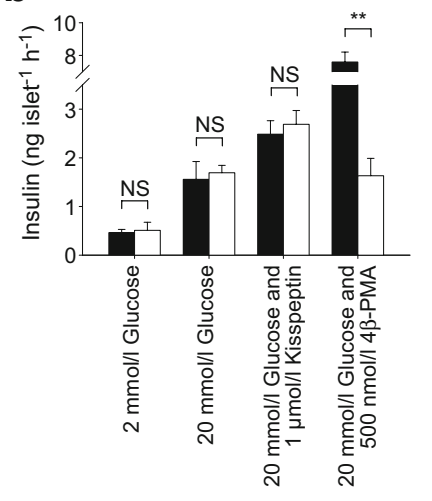

d

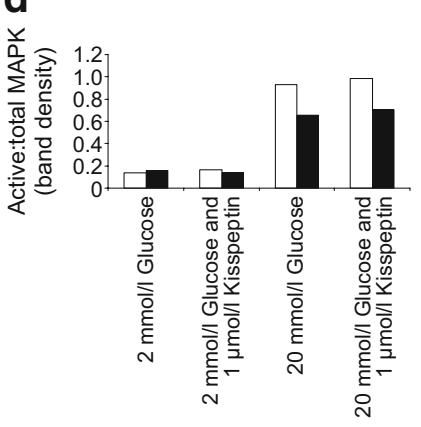

Fig. 3 Intracellular signalling pathways mediating the effects of kisspeptin in islets. a The PLC inhibitor, U73122, and the p42/44 MAPK inhibitor, PD098059, both completely blocked the potentiation of glucose-stimulated insulin release caused by kisspeptin in mouse islets. The PKC inhibitor, Gö6976, and the p38 inhibitor, SB203580, had no inhibitory effect on the kisspeptin potentiation of insulin release. Results from systems with $100 \mathrm{nmol} / 1$ kisspeptin are shown in black, and those from systems without kisspeptin are shown in white. Mean \pm SEM, $n=9,{ }^{*} p<0.01$ vs $20 \mathrm{mmol} / 1$ glucose without kisspeptin. b PKC downregulation by $24 \mathrm{~h}$ incubation in the presence of $500 \mathrm{nmol} / 1$ 4 $\beta$-PMA (white bars) had no effect on insulin release from isolated islets stimulated by $20 \mathrm{mmol} / \mathrm{l}$ glucose or $1 \mu \mathrm{mol} / 1$ kisspeptin compared with release from islets incubated for $24 \mathrm{~h}$ with inactive $4 \alpha$-PMA (black bars). However, $24 \mathrm{~h}$ incubation in $4 \beta$-PMA completely blocked the stimulation of insulin release caused by acute exposure to $500 \mathrm{nmol} / 14 \beta$-PMA. Mean \pm SEM, $n=9$, $* * p<0.01$ vs $4 \alpha$-PMA controls. c Phosphorylated p42/44 MAPK immunoreactivities (upper panel) and total p42/44 MAPK immunoreactivities (lower panel) were detected in extracts of mouse islets incubated for $5 \mathrm{~min}$ at $37^{\circ} \mathrm{C}$. Arrows show molecular mass calculated from the gel migration positions of proteins of known molecular mass. The figure shows one experiment that was reproduced three times using different samples. d Band densities were quantified for both $\mathrm{p} 42$ (white bars) and p44 (black bars) MAPK and expressed as a ratio of active:total MAPK

and $100 \mu \mathrm{mol} / 1$ tolbutamide, which were most likely to be beta cells, were included in the analysis.

Effect of peripheral and central kisspeptin on insulin secretion in vivo When administered via an i.v. injection, $37.5 \mathrm{nmol}$ kisspeptin produced an increase of $11.8 \mathrm{ng} / \mathrm{ml}$ $(9 \mathrm{nmol} / \mathrm{l})$ in circulating plasma kisspeptin levels and caused an approximately fourfold increase in plasma insulin lasting for longer than $90 \mathrm{~min}$ in conscious adult rats

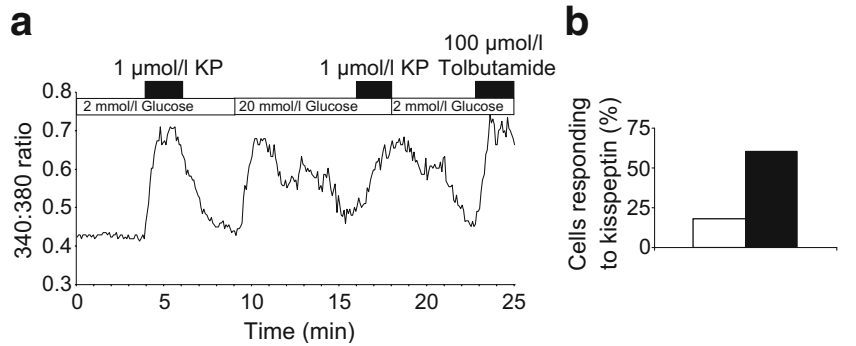

Fig. 4 Kisspeptin effects on intracellular calcium in islet cells. a Administration of $1 \mu \mathrm{mol}$ kisspeptin increases $\left[\mathrm{Ca}^{2+}\right]_{\mathrm{i}}$ in dispersed mouse islet cells that respond to both $20 \mathrm{mmol} / \mathrm{l}$ glucose and $100 \mu \mathrm{mol} / \mathrm{l}$ tolbutamide. The trace is representative of seven separate experiments. b Percentage of cells that exhibited an increase in $\left[\mathrm{Ca}^{2+}\right]_{\mathrm{i}}$ in response to $1 \mu \mathrm{mol} / \mathrm{l}$ kisspeptin at either $2 \mathrm{mmol} / \mathrm{l}$ glucose (white bar) or $20 \mathrm{mmol} / 1$ glucose (black bar) $\mathrm{KP}$, kisspeptin

without any significant change in blood glucose levels (Fig. 5a). In contrast, kisspeptin had no significant effect on plasma insulin when administered centrally via an i.c.v. cannula (Fig. 5b).

\section{Discussion}

The role of hypothalamic kisspeptin in the reproductive axis is well established, but the effects of kisspeptin in peripheral tissues remain relatively unknown. The results presented here confirm our previous preliminary report that
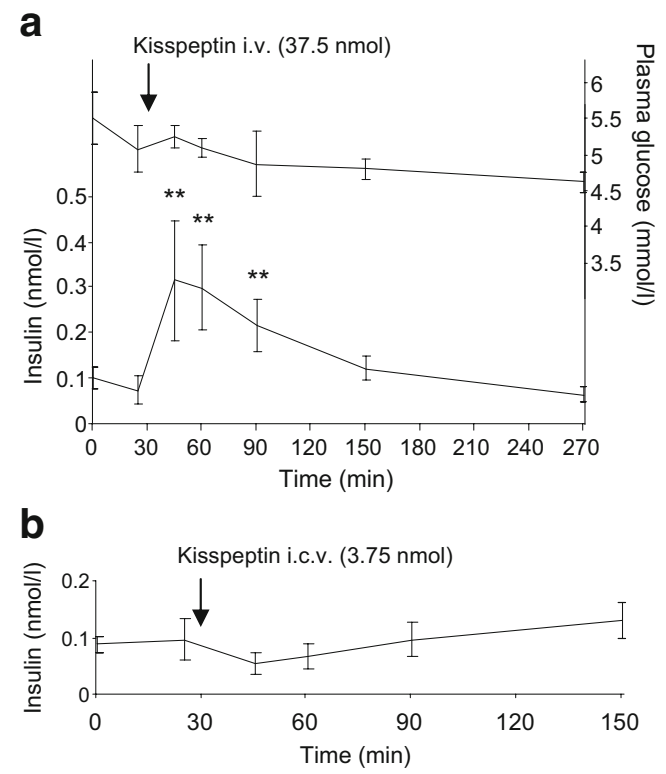

Fig. 5 In vivo effects of kisspeptin on insulin secretion. a Intravenous administration of kisspeptin caused a rapid increase in plasma insulin levels lasting over $90 \mathrm{~min}$, but caused no significant change in plasma glucose. b Intracerebroventricular administration of kisspeptin had no effect on plasma insulin. Mean \pm SEM, $n=5-7,{ }^{* *} p<0.01$ vs pretreatment control values 
exogenous kisspeptin potentiated glucose-induced insulin secretion from isolated mouse islets [8], and further characterise this action. In the present study, kisspeptin enhanced both the first and second phases of the glucoseinduced secretory response, but did not initiate a secretory response in the absence of a stimulatory concentration of glucose, consistent with the mode of action of many receptor-operated agonists that modulate the amplitude of nutrient-induced insulin secretory responses. The stimulatory effects of kisspeptin on insulin secretion were fully reversible, again consistent with a receptor-mediated action, and the islets were subsequently able to maintain glucoseinduced insulin secretion suggesting that kisspeptin had no deleterious effects on the beta cells.

Little information is yet available about the biologically active concentrations of kisspeptin, and there are at least two possible sources of kisspeptin that may activate the beta cell GPR-54. Circulating levels of kisspeptin in humans are normally very low but increase markedly during pregnancy, and this circulating kisspeptin is assumed to be of placental origin [19]. Peak kisspeptin concentrations of approximately $2.5 \mathrm{nmol} / 1$ are detected during the third trimester in humans [19], but this is still somewhat lower than the concentrations of approximately $50 \mathrm{nmol} / 1$ that were required to stimulate insulin secretion from mouse islets in our in vitro experiments. To date there is no information about placental production or circulating levels of kisspeptin in mice, so it is possible that plasma kisspeptin levels during pregnancy reach higher levels in mice with their multiple placentas. Alternatively, it may be that islet GPR-54 is expressed to respond to locally released kisspeptin, as occurs in the hypothalamus, and our demonstration of the co-expression of kisspeptin and GPR-54 in islets is consistent with an intra-islet paracrine role for kisspeptin [8]. The concentration of a para/autocrine agent that will be achieved at its local sites of release and action is difficult to assess, but it is likely to be considerably higher than the concentration of the same agent in the peripheral circulation. This may explain why the potentiation of insulin release from isolated mouse islets required kisspeptin concentrations of around $50 \mathrm{nmol} / \mathrm{l}$, which is considerably higher than the peripheral circulating concentrations of most peptide hormones.

Although the source of the kisspeptin that activates beta cell GPR-54 is uncertain, our results clearly demonstrate directly stimulatory effects of GPR-54 activation on nutrient-induced insulin secretion from isolated islets. The intracellular mechanisms involved in the effects of kisspeptin on beta cells are currently unknown, although a number of studies have investigated kisspeptin signalling in the hypothalamus $[20,21]$ and in tumour cell lines $[1,22]$. Our experiments showed that kisspeptin had rapid stimulatory effects on beta cell cytosolic $\mathrm{Ca}^{2+}$, and that the effects of kisspeptin on insulin secretion were blocked by a PLC inhibitor, suggesting that kisspeptin potentiates glucoseinduced insulin release from beta cells through GPR-54linked PLC activation and increases in intracellular $\mathrm{Ca}^{2+}$, most likely through the generation of inositol triphosphate and subsequent liberation of $\mathrm{Ca}^{2+}$ from the endoplasmic reticulum. This signalling pathway has previously been shown to play an important role in mediating the effects of kisspeptin on gonadotrophin-releasing hormone release in the hypothalamus [20], suggesting some overlap in the intracellular pathways involved in the effects of kisspeptin in different tissues. Increases in intracellular $\mathrm{Ca}^{2+}$ were not observed in all beta cells in response to kisspeptin administration, suggesting functional heterogeneity among islet beta cells at the level of GPR-54 production or its intracellular coupling. This is not too surprising since it is well known that individual beta cells are heterogeneous and differ in their sensory [23], biosynthetic [24, 25], intracellular $\mathrm{Ca}^{2+}[26,27]$ and secretory [28] responses. PLC activation is also associated with the generation of DAG and the subsequent activation of DAG-sensitive isoforms of protein kinase $\mathrm{C}$, an important mechanism in the stimulation of insulin release by some receptor-mediated stimuli [22], including acetylcholine [17, 18] and cholecystokinin [29]. However, our results do not support a role for this pathway in mediating the effects of kisspeptin on beta cells. An inhibitor of the DAG-sensitive PKC isoforms (Gö6976) had no effect on kisspeptin-dependent potentiation of glucose-induced insulin release from isolated islets, and downregulating islet content of DAG-sensitive PKC isoforms by prolonged exposure to $4 \beta$-PMA $[17,18,30] \mathrm{did}$ not reduce the effects of kisspeptin on insulin secretion.

The p38 and p42/44 MAPK transduction cascades have been implicated in the effects of kisspeptin in hypothalamic neurones and in the CHO-K1 tumour cell line $[1,20]$, and the p42/44 MAPK pathway is important in mediating the effects of the calcium-sensing receptor on insulin release from beta cells [13]. Whilst the p38 MAPK pathway is involved in mediating the effects of kisspeptin on secretion of gonadotrophin-releasing hormone in the hypothalamus [20], the p38 inhibitor, SB203580, had no effect on kisspeptin-induced insulin secretion in our experiments, suggesting that the intracellular systems through which kisspeptin acts on cells may be tissue specific. However, the results of the current study demonstrated that a p42/44 MAPK inhibitor, PD98059, completely blocked the effects of kisspeptin on insulin release, suggesting an involvement of this pathway in beta cells. The effects of p42/44 MAPK activation appear to be permissive rather than causal for kisspeptin-induced insulin secretion. Thus, the presence of a stimulatory concentration of glucose enhanced p42/44 MAPK activation, as has been reported previously [31, 32], and pharmacological inhibition of this activation blocked 
kisspeptin-induced insulin secretion in vitro. In contrast, kisspeptin had no effect on p42/44 MAPK phosphorylation irrespective of the ambient glucose concentration, suggesting that glucose-induced p42/44 MAPK activation is required for the potentiating effects of kisspeptin on insulin secretion, although p42/44 activation alone is insufficient to initiate a secretory response [31,32]. These observations are consistent with a model in which nutrient-induced activation of p42/44 MAPK is not directly involved in the initiation of nutrient-induced insulin secretion, but enables the potentiation of nutrient-induced secretory responses by some receptor-operated stimuli, such as kisspeptin.

In contrast with the observed effects of kisspeptin to potentiate glucose-induced insulin secretion from isolated islets in vitro, a recent report suggests that kisspeptin inhibits the release of insulin from the perfused pancreas [33], raising the possibility that the effects of kisspeptin on islet function may be influenced by the in vivo environment. To determine whether the results obtained from our in vitro experiments in the present study are representative of the effects of kisspeptin on pancreatic islets in vivo, doses of kisspeptin previously shown to stimulate luteinising hormone release $[15,16]$ were administered to conscious, unrestrained rats. The results clearly demonstrated that exogenous kisspeptin stimulated insulin release in vivo in conscious rats, confirming the stimulatory effects on isolated islets in vitro. The immediate and sustained increase in plasma insulin levels induced by kisspeptin was not accompanied by detectable changes in blood glucose, presumably reflecting intact autoregulatory mechanisms in this model using non-anaesthetised, unrestrained animals. The unchanged levels of blood glucose also point to a direct effect of kisspeptin on pancreatic beta cells to stimulate insulin release, rather than a secondary effect through increasing blood glucose levels. Additionally, central administration of kisspeptin had no effect on plasma insulin, suggesting that the stimulation of insulin release by kisspeptin is mediated through a peripheral, as opposed to central, site of action. In both in vivo and in vitro experiments the effects of kisspeptin on insulin secretion were fully reversible, consistent with an effect mediated through the activation of a G-protein-coupled cell-surface receptor, such as GPR-54. The relatively prolonged effects of kisspeptin on insulin secretion in vivo and in vitro is in accordance with previous studies demonstrating sustained effects of kisspeptin in the hypothalamus for over $1 \mathrm{~h}$ after administration [15, 34]. Measurements using a commercially available assay suggested that the intravenous administration schedule used in our in vivo experiments produced increases in plasma kisspeptin $(9 \mathrm{nmol} / \mathrm{l})$ of the same order of magnitude as the physiological increases ( $2.5 \mathrm{nmol} / \mathrm{l})$ reported in pregnant women [19], suggesting that there are circumstances where circulating kisspeptin could influence islet function. However, some caution is required in interpreting these data, since plasma kisspeptin can be difficult to measure accurately [35]. In the current study we used a human kisspeptin assay because there are no available assays for rat kisspeptin and the inter-species specificity of the assay is unknown. Irrespective of the absolute concentrations of kisspeptin achieved in our in vivo experiments, the kisspeptin-induced increase in plasma insulin suggests that in the whole animal, as in isolated islets, kisspeptin has a stimulatory effect on insulin release. It is unclear why an inhibitory effect is seen in the perfused pancreas model [33], and further work is required to determine the factors responsible for differences between the observed effects in different models.

Our in vitro studies demonstrated that the stimulatory effects of kisspeptin on insulin secretion were dependent on the presence of a stimulatory concentration of glucose, consistent with the known mechanisms of many other receptor-operated agonists which potentiate nutrient-induced secretion but do not initiate a secretory response [36]. In contrast, kisspeptin administration in vivo markedly increased plasma insulin levels in animals with normal non-fasted blood glucose levels. There are several possible reasons for our in vivo observations. Thus, it is difficult to extrapolate from precisely defined experimental conditions in vitro to the much more complex in vivo environment in which, for example, islets are exposed simultaneously to many circulating nutrients and non-nutrient stimuli, and to the influence of intact innervation. In addition, it is difficult to compare the concentrations of kisspeptin to which the islets are exposed in vitro and in vivo without detailed knowledge of the pharmacokinetics of kisspeptin after single intravenous administration, so the observed differences in the degree of glucose-dependency may reflect differences in the concentrations of kisspeptin to which the islets have been exposed.

In conclusion, pancreatic islets express both kisspeptin and its receptor GPR-54, suggesting an important role in the control of islet function; this is supported by our in vivo and in vitro observations of the stimulatory effects of exogenous kisspeptin on insulin secretion. The known involvement of kisspeptin in puberty $[4,5]$ and pregnancy $[37,38]$, and in mediating the effects of nutritional status on reproductive function [6, 7] raises the possibility that kisspeptin plays multiple roles as a physiological regulator of whole body fuel homeostasis, at least partly by regulating islet function.

Acknowledgements This work was supported by the Diabetes Research and Wellness Foundation (DRWF) and Diabetes UK. J. E. Bowe is a DRWF Research Fellow. A. J. King is a recipient of a Research Council UK fellowship.

Duality of interest The authors declare that there is no duality of interest associated with this manuscript. 


\section{References}

1. KotaniFventi M, Detheux M, Vandenbogaerde A et al (2001) The metastasis suppressor gene KiSS-1 encodes kisspeptins, the natural ligands of the orphan G protein-coupled receptor GPR54. J Biol Chem 276:34631-34636

2. Muir AI, Chamberlain L, Elshourbagy NA et al (2001) AXOR12, a novel human $G$ protein-coupled receptor, activated by the peptide KiSS-1. J Biol Chem 276:28969-28975

3. Ohtaki T, Shintani Y, Honda S et al (2001) Metastasis suppressor gene KiSS-1 encodes peptide ligand of a G-protein-coupled receptor. Nature 411:613-617

4. de Roux N, Genin E, Carel JC, Matsuda F, Chaussain JL, Milgrom E (2003) Hypogonadotropic hypogonadism due to loss of function of the KiSS1-derived peptide receptor GPR54. Proc Natl Acad Sci U S A 100:10972-10976

5. Seminara SB, Messager S, Chatzidaki EE et al (2003) The GPR54 gene as a regulator of puberty. N Engl J Med 349:1614-1627

6. Castellano JM, Navarro VM, Fernandez-Fernandez R et al (2005) Changes in hypothalamic KiSS-1 system and restoration of pubertal activation of the reproductive axis by kisspeptin in undernutrition. Endocrinology 146:3917-3925

7. Smith JT, Acohido BV, Clifton DK, Steiner RA (2006) KiSS-1 neurones are direct targets for leptin in the ob/ob mouse. J Neuroendocrinol 18:298-303

8. Hauge-Evans AC, Richardson CC, Milne HM, Christie MR, Persaud SJ, Jones PM (2006) A role for kisspeptin in islet function. Diabetologia 49:2131-2135

9. Luther MJ, Hauge-Evans A, Souza KL et al (2006) MIN6 beta-cellbeta-cell interactions influence insulin secretory responses to nutrients and non-nutrients. Biochem Biophys Res Commun 343:99-104

10. Gey GO, Gey MK (1936) Maintenance of human normal cells in continuous culture: preliminary report; cultivation of mesoblastic tumours and normal cells and notes on methods of cultivation. Am J Cancer 27:45-76

11. Jones PM, Salmon DM, Howell SL (1988) Protein phosphorylation in electrically permeabilized islets of Langerhans. Effects of $\mathrm{Ca}^{2+}$, cyclic AMP, a phorbol ester and noradrenaline. Biochem J 254:397-403

12. Persaud SJ, Roderigo-Milne HM, Squires PE et al (2002) A key role for beta-cell cytosolic phospholipase $\mathrm{A}(2)$ in the maintenance of insulin stores but not in the initiation of insulin secretion. Diabetes 51:98-104

13. Gray E, Muller D, Squires PE et al (2006) Activation of the extracellular calcium-sensing receptor initiates insulin secretion from human islets of Langerhans: involvement of protein kinases. J Endocrinol 190:703-710

14. Li XF, Bowe JE, Mitchell JC, Brain SD, Lightman SL, O'Byrne KT (2004) Stress-induced suppression of the gonadotropinreleasing hormone pulse generator in the female rat: a novel neural action for calcitonin gene-related peptide. Endocrinology $145: 1556-1563$

15. Kinsey-Jones JS, Li XF, Luckman SM, O'Byrne KT (2008) Effects of kisspeptin-10 on the electrophysiological manifestation of gonadotropin-releasing hormone pulse generator activity in the female rat. Endocrinology 149:1004-1008

16. Thompson EL, Patterson M, Murphy KG et al (2004) Central and peripheral administration of kisspeptin-10 stimulates the hypothalamic-pituitary-gonadal axis. J Neuroendocrinol 16:850-858

17. Persaud SJ, Jones PM, Sugden D, Howell SL (1989) Translocation of protein kinase $\mathrm{C}$ in rat islets of Langerhans. Effects of a phorbol ester, carbachol and glucose. FEBS Lett 245:80-84

18. Persaud SJ, Jones PM, Sugden D, Howell SL (1989) The role of protein kinase $\mathrm{C}$ in cholinergic stimulation of insulin secretion from rat islets of Langerhans. Biochem J 264:753-758
19. Dhillo WS, Savage P, Murphy KG et al (2006) Plasma kisspeptin is raised in patients with gestational trophoblastic neoplasia and falls during treatment. Am J Physiol Endocrinol Metab 291:E878-E884

20. Castellano JM, Navarro VM, Fernandez-Fernandez R et al (2006) Ontogeny and mechanisms of action for the stimulatory effect of kisspeptin on gonadotropin-releasing hormone system of the rat. Mol Cell Endocrinol 257-258:75-83

21. Murphy KG (2005) Kisspeptins: regulators of metastasis and the hypothalamic-pituitary-gonadal axis. J Neuroendocrinol 17:519-525

22. Jiang Y, Berk M, Singh LS et al (2005) KiSS1 suppresses metastasis in human ovarian cancer via inhibition of protein kinase C alpha. Clin Exp Metastasis 22:369-376

23. Kiekens R, In't Veld P, Mahler T, Schuit F, Van De WM, Pipeleers D (1992) Differences in glucose recognition by individual rat pancreatic B cells are associated with intercellular differences in glucose-induced biosynthetic activity. J Clin Invest 89:117-125

24. Bosco D, Meda P (1991) Actively synthesizing beta-cells secrete preferentially after glucose stimulation. Endocrinology 129:31573166

25. Schuit FC, In't Veld PA, Pipeleers DG (1988) Glucose stimulates proinsulin biosynthesis by a dose-dependent recruitment of pancreatic beta cells. Proc Natl Acad Sci U S A 85:3865-3869

26. Squires PE, Hauge-Evans AC, Persaud SJ, Jones PM (2000) Synchronization of $\mathrm{Ca}(2+)$-signals within insulin-secreting pseudoislets: effects of gap-junctional uncouplers. Cell Calcium 27:287-296

27. Squires PE, Persaud SJ, Hauge-Evans AC, Gray E, Ratcliff H, Jones PM (2002) Co-ordinated $\mathrm{Ca}(2+)$-signalling within pancreatic islets: does beta-cell entrainment require a secreted messenger. Cell Calcium 31:209-219

28. Stefan Y, Meda P, Neufeld M, Orci L (1987) Stimulation of insulin secretion reveals heterogeneity of pancreatic B cells in vivo. J Clin Invest 80:175-183

29. Persaud SJ, Jones PM, Howell SL (1993) Stimulation of insulin secretion by cholecystokinin-8S: the role of protein kinase C. Pharm Comm 3:39-47

30. Jones PM, Persaud SJ (1998) Protein kinases, protein phosphorylation, and the regulation of insulin secretion from pancreatic beta-cells. Endocr Rev 19:429-461

31. Arnette D, Gibson TB, Lawrence MC et al (2003) Regulation of ERK1 and ERK2 by glucose and peptide hormones in pancreatic beta cells. J Biol Chem 278:32517-32525

32. Burns CJ, Howell SL, Jones PM, Persaud SJ (1997) Glucosestimulated insulin secretion from rat islets of Langerhans is independent of mitogen-activated protein kinase activation. Biochem Biophys Res Commun 239:447-450

33. Silvestre RA, Egido EM, Hernandez R, Marco J (2008) Kisspeptin-13 inhibits insulin secretion without affecting glucagon or somatostatin release: study in the perfused rat pancreas. J Endocrinol 196:283-290

34. Han SK, Gottsch ML, Lee KJ et al (2005) Activation of gonadotropin-releasing hormone neurons by kisspeptin as a neuroendocrine switch for the onset of puberty. J Neurosci 25:11349-11356

35. Ramachandran R, Patterson M, Murphy KG et al (2008) Preanalytical factors affecting RIA measurement of plasma kisspeptin. Clin Chem 54:615-617

36. Flatt PR (2003) The hormonal and neural control of endocrine pancreatic function. In: Pickup JC, Williams G (eds) Textbook of diabetes, 3rd edn. Blackwell, Oxford, pp 11.1-11.11.21

37. Hiden U, Bilban M, Knofler M, Desoye G (2007) Kisspeptins and the placenta: regulation of trophoblast invasion. Rev Endocr Metab Disord 8:31-39

38. Roa J, Vigo E, Castellano JM et al (2006) Hypothalamic expression of KiSS-1 system and gonadotropin-releasing effects of kisspeptin in different reproductive states of the female rat. Endocrinology 147:2864-2878 